\title{
Editorial: use of surgical databases in urogynaecology
}

\author{
Abdelmageed Abdelrahman ${ }^{1} \cdot$ Ashleigh Moore ${ }^{2} \cdot$ Ruben Trochez ${ }^{1}$ \\ Received: 23 June 2018 / Accepted: 27 March 2019 / Published online: 29 April 2019 \\ (C) The International Urogynecological Association 2019
}

\section{Introduction}

In recent years, there has been an increase in the use of surgical databases to record the outcomes of surgery in many specialties. Urogynaecology has seen the development of at least two large-scale databases in the last two decades.

This editorial addresses the rationale for a surgical database in urogynaecology, how the database works, the advantages and drawbacks of this form of data collection, usage, and the potential it has to become a compulsory and perhaps essential element of urogynaecological practice.

\section{Rationale for a surgical database}

The basic principle of a surgical database is to audit the outcomes of surgery to raise the standards of care and enhance clinical governance, both at an individual and an organisational level. In 2007, the British Society of Urogynaecology (BSUG) launched BSUG.NET, the first online urogynaecology database of its kind [1]. Since its launch, the BSUG database has received the backing of healthcare organisations in the UK, particularly the National Institute for Health and Clinical Excellence (NICE), which recommends its use. Similarly in Denmark, we have seen the evolution of "DugaBase" in 2006 and in the USA, the AQUIRE database is used by members of the American Urogynecology Society (AUGS). The International Urogynaecology Association (IUGA) offers gynaecologists use of one of the largest international surgical databases to record their pre-, intra- and post-operative data [2].

Abdelmageed Abdelrahman

abdelmageed@hotmail.co.uk

1 Liverpool Women's Hospital NHS Foundation Trust, Liverpool, UK

2 Poole Hospital NHS Foundation Trust, Poole, UK

\section{How the database works}

Both the BSUG and the IUGA databases have a user-friendly, secure, online interface that allows the user to collect pre-, intra- and post-operative data relating to surgical procedures for incontinence and prolapse. Access is available to all their members, but use of the databases is voluntary. However, this is not uniform across all countries. In Denmark, the law requires urogynaecologists to enter their procedure-based information into DugaBase. Users of the BSUG and IUGA databases are only able to access data and run reports on their own patients. Importantly, users of the BSUG database have basic access to all data uploaded to BSUG.NET and can obtain further information for audit, presentation and/or publication through a formalised application process.

With regard to the issue of gaining patient consent for sharing UK data on BSUG.NET, each patient completes and signs a consent form, often at the same time as giving consent to the operation. In contrast, individual consent is not required when sharing data on DugaBase [3].

A basic level of patient-identifiable data is entered (name, date of birth and hospital number), but reports are anonymised with regard to patient, surgeon and centre. Pre- and intraoperative fields are ideally completed at the time of the operation. Patients who are already on the system having had previous surgery are archived within the system so that patientidentifiable data does not need to be entered for each surgical episode.

\section{Benefits of using the database}

The use of a surgical database in urogynaecology has many advantages. The BSUG database collects data from the centres and surgeons who voluntarily contribute it to the database throughout the UK and provides a large dataset with regard to procedure numbers, complications and outcome measures using validated measures. This helps to produce clinically useful data. 
The information contained within one's own dataset is extremely helpful with respect to personal development and appraisal. It is particularly helpful when surgeons are monitoring the introduction into practice of new procedures.

From a trainee's perspective, it is a useful adjunct in documenting data relating to their surgical performance and learning curve.

In the UK, utilisation of the BSUG database forms an integral part of the process of formal accreditation of units providing urogynaecology services.

\section{Disadvantages of databases}

The database does have some shortcomings, however. A potential drawback of the use of voluntary databases is the "user dependent" nature of the information entered. The quality of the data entered can be affected by many factors, including time constraints and selectiveness by the users with regard to how much data they enter, amongst other issues. In an ideal setting, information would be collected and entered by an objective third party to minimise bias and inaccuracy. However, the additional work for existing staff, or the need for additional staffing, with its financial implications, could discourage surgeons and centres from using the database in this model. One option is to follow Denmark's example and make it compulsory practice.

Other challenges include the need to standardise the reporting format of cases to ensure that it is amenable to comparison. Ideally, this would mean that every surgeon would use the same national, if not international, database for their recording.

Although entering initial information on procedures is relatively straightforward, entering data on follow-up outcomes is more challenging. Barriers to gathering follow-up information include time constraints and missing or incomplete data for follow-up.

Lastly, although auditing large volumes of data from a database is likely to give statistically significant results, this does not always translate into clinical change.

\section{The future...}

Using a database to record surgical cases is likely to be a relatively novel concept to many trainees and perhaps established specialists; however, it should be part of routine practice for gynaecologists performing prolapse and/or incontinence surgery. Clinical governing bodies in Europe and the USA have recommended the use of databases; therefore, it is imperative for healthcare providers to take a proactive approach to supporting this recommendation.

A database is a useful tool for auditing surgical data locally, nationally and internationally. Importantly, it can help to determine complications earlier and respond to concerns from regulatory bodies such as the Medicines and Healthcare products Regulatory Agency (MHRA) of the United Kingdom and the Food and Drug Administration (FDA) of the United States of America. The recent surge in the reporting of complication rates in the use of vaginal mesh in surgery to correct prolapse and stress urinary incontinence has led to a call for more meticulous recording of individual surgical data. This has strengthened the call for making the recording of surgical data compulsory within urogynaecology practice in the UK [4].

Improvements in the standardisation of data would likely make the process of entering clinical information less taxing. In our increasingly busy and complicated work environments, a system that is secure, simple and that has a positive impact on patient outcomes is likely to be welcomed by all.

\section{Compliance with ethical standards}

Conflicts of interest Ruben Trochez: chair of the BSUG IT Committee, member of the BSUG Committee and Consultancy Boston Scientific. The other authors have no conflicts of interest to declare.

\section{References}

1. Moran P, Foon R, Assassa P. The BSUG national database: concept, design, implementation and beyond. Obstet Gynaecol. 2013;15:120 7.

2. The International Urogynaecological Association Surgical Database. https://new.iuga.org/tools/surgical-database/. Accessed on 27 March 2018.

3. Hansen UD, Gradel KO, Larsen MD. Danish Urogynaecological Database. Clin Epidemiol. 2016;8:709-12..

4. BSUG Audit Database \& HQIP. British Society of Urogynaecology. 2014. http://bsug.org.uk/news-details/bsug-audit-database $\%$ E2\% 80\%93hqip/43/12/0. Accessed on 27 March 2018.

Publisher's note Springer Nature remains neutral with regard to jurisdictional claims in published maps and institutional affiliations. 